\title{
Research on the Excellent Talents Training Plan of Information Management Based on Social Demands
}

\author{
Xiang-shuo He \\ North China Electric Power University, Baoding, China
}

\begin{abstract}
Keywords: Information management, Excellent talents, Training plan, Course system, Practical
\end{abstract} teaching system

\begin{abstract}
From the perspective of meeting the needs of the society, combining with the employment situation of the information management graduates and the information management excellent talent training plan, this paper puts forward the excellent talents training plan of information management based on social demands. It is pointed out that under the guidance of the clear training target, the students' ability cultivation should be the core task, and reform should be carried out from the theoretical teaching mode and the practical teaching mode. The reform initiatives of information management are discussed from the training mode, training program, curriculum system, teaching staff and practice internship aspect.
\end{abstract}

\section{Introduction}

Information management and information system is an emerging cross-disciplinary. In today's information age, society needs the compound-type expertise who master the modern management science, economics, computer science and technology theory knowledge and basic skills, and can undertake information system analysis, design, implementation and management [1]. According to the statistics of relevant departments, at present, the gap of high-level talents who engage in information analysis in China has reached 300 million people, which form the "information analyst" urgent needs. Among 3,000 large enterprises in China, only 3.7\% of them have the mature information management technology [2]. However, in contrast to the strong demand for information management talents, the low employment rate and employment satisfaction of the students in information management, and the increase in the overall employment pressure caused by enrollment expansion, can still be seen. How to cultivate the information management talents to meet the social needs and how to eliminate the gap between market demand and personnel training have become an urgent problem in the field of information management education.

\section{Orientation of Excellent Talents Cultivation Plan for Information Management Major}

In order to promote our country change from engineering education power to engineering education, in 2010 the Ministry of education with relevant departments and industry associations jointly launched the university talent cultivation project "excellent engineer education plan" [3]. This plan has three characteristics: Depth participation in the training process; schools in accordance with common standards and industry standards to cultivate engineering talent; strengthen the students' engineering and innovation. Local engineering colleges are the important carrier of mass higher education in our country and the important educational resource and talent cultivation base of local economic and social development. Therefore, in the training of information management major, it should be in accordance with the promulgation of the "Excellent engineer education program," and build a system of professional personnel training program.

Through the in-depth study of information management major, the information management major of our university should grasp the idea of running modern education and local economic development, 
regard the social demands as the guide, and implement the cultivation policy of facing to engineering, wide base, strong ability, and paying attention to application. Put the actual project as the background, combining with the comprehensive advantages and characteristics of information management and information systems major in our college, train the high-level compound talents that master the theoretical basis of modern management and computer science and technology knowledge and application capabilities, the system ideas and information systems analysis and design methods and information management and other aspects of knowledge and ability, focus on the development of information systems, information management and information systems with a solid theoretical basis. In addition, they can be access to complete engineering and technical training, and be with innovative spirit and practical ability based on real ability and high-quality.

\section{Analysis on the Key Points of Excellent Personnel Training Plan of Information Management Major}

Build Reasonable Talents Training System Based on Engineering Quality. According to the needs of social and economic development, the local enterprises shall be informed of the demand for the knowledge structure of information management major, and the local industry and employing departments shall be actively involved in the reform and development of information management major training programs [4]. To engineering quality-oriented, pay attention to the classroom and extra-curricular, the combination with school and outside. The talents training system is design as Fig. 1.

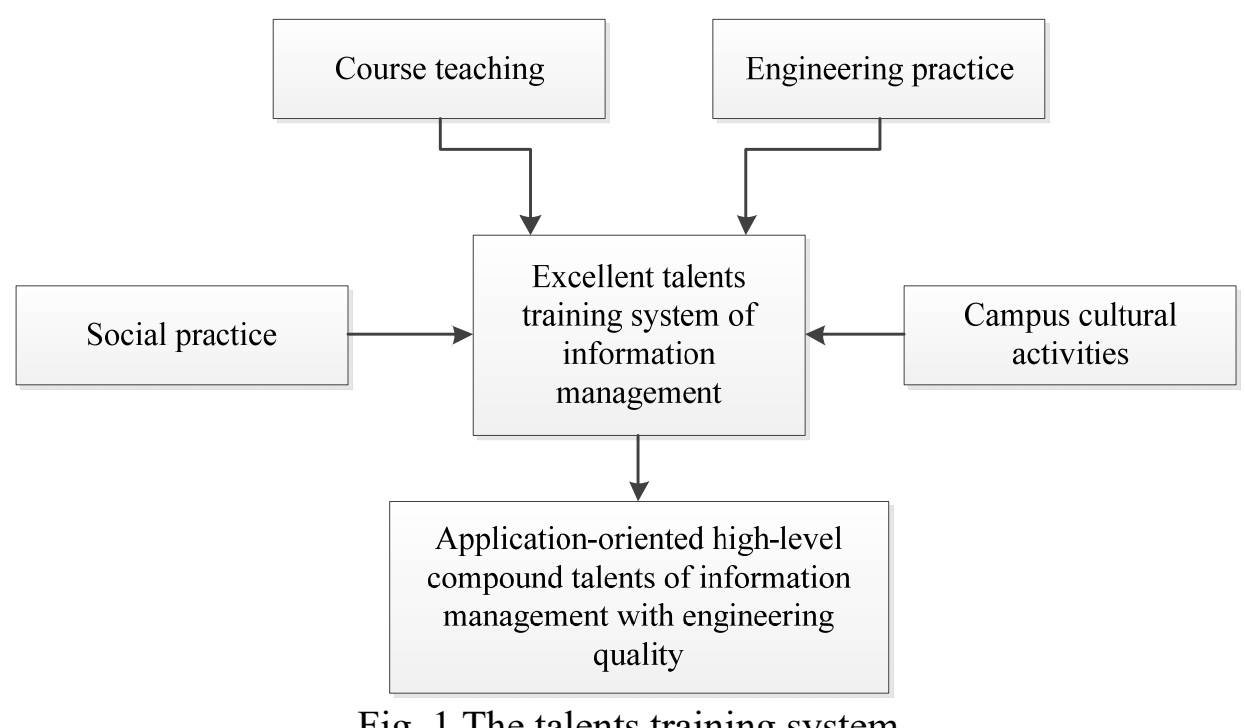

Fig. 1 The talents training system

Build the "Capacity-Based" Theory Teaching System Based on Major Training Objectives. The "ability-based" mode of education is based on the social needs. In the construction of the curriculum system from the practical point of view, it should focus on strengthening the students' ability of information management application, so that students have engaged in information management related positions the basic ability. The construction of the curriculum system is the key and difficult point of the teaching reform. It is the key to realize the professional training goal, cultivate the applied talents and compound talents. The construction of the course system of information management should be based on the principle of scientificity, theory and practice, stability and dynamic. In the course setting, around the "ability-based" theory teaching system, based on training objectives, from the emphasis on technology courses to technology and management both to increase the proportion of elective courses, improve the ability of students to adapt to the job requirements. The construction of the course system is shown in Fig. 2. 


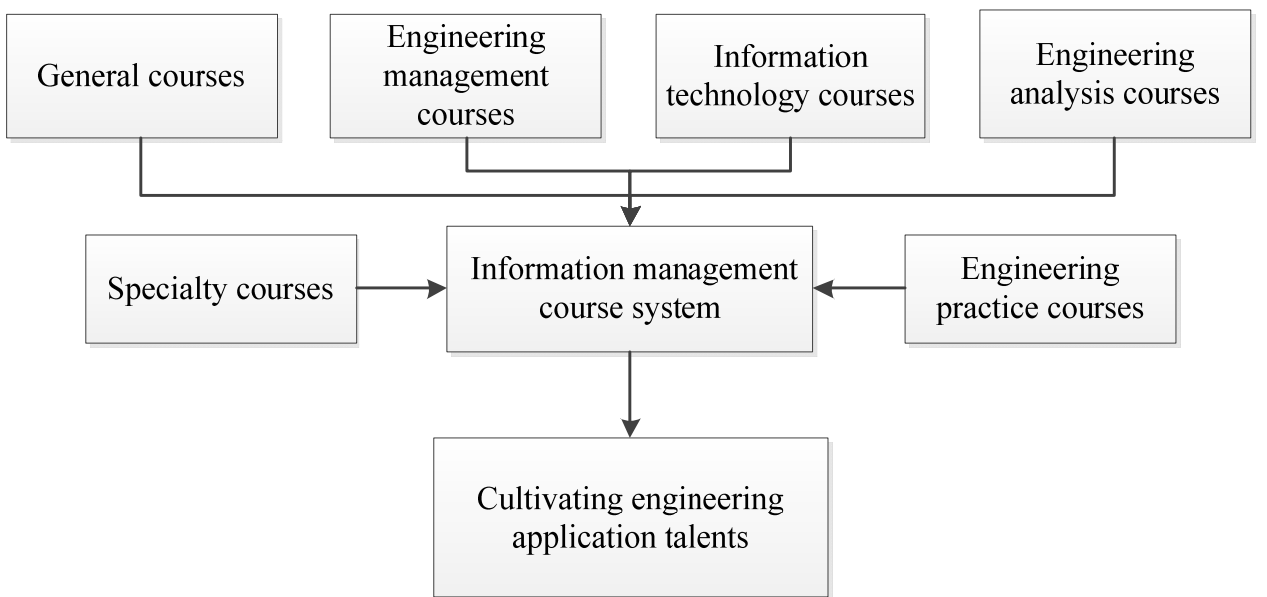

Fig. 2 Excellent talents training course system of information management major

The course system of information management talents training is based on the general course, engineering management course, information technology course and engineering practice course, with specialty courses and engineering practice courses as the two wings. Through the integration of these six courses, students' comprehensive abilities of system development, implementation, management and application are trained. Various courses in the specific role of personnel training are as follows:

General curriculum: Mainly including 5 course modules: the ideological and political courses, language basic courses, sports and military courses, general courses and literature and art training courses, which are existing natural science knowledge and humanities and social science knowledge. They can enhance students' cultural quality, improve the personality construction, and balance the knowledge structure.

Project management course: Mainly cultivate students' ability and quality in organization, coordination, personnel, leadership, behavior and economic management. The main courses include information management foundation, management principle, economics principle, statistics, IT project management, organization Behavior, information economics.

Information technology courses: Mainly cultivate students' ability of developing programming, information systems and maintenance of the technical foundation. The main courses are $\mathrm{C}$ language programming, computer composition principle, data structure, operating system, database system theory, computer network, object-oriented programming $(\mathrm{C}++)$, Unix operating system, network architecture technology, Java development technology, VC development technology, information security technology.

Engineering analysis courses: mainly solve the engineering practice of modeling, quantitative analysis and systematic analysis to solve system design problems. The main courses are higher mathematics, linear algebra, probability theory and data statistics, operations research, IT project management, information systems Analysis and design, mathematical modeling.

Specialized courses: Mainly based on the training objectives, forward-looking and practical orientation for the course, the creation of a clear ability to develop features and employment expertise courses, highlighting the outstanding engineering analysis and implementation of capacity training. The main courses include information systems development, software engineering, mathematical modeling, ERP principles and practice, e-commerce technology, database application development technology, information retrieval, database and data mining, database design, software project management.

Engineering practice courses: Mainly to enable students to accumulate project management and operational experience. The main courses are project management, enterprise team management, IT project management, IT project implementation, software engineering practice.

Deepen the Practice of Teaching Reform, Innovate Talents Training Model, and Build Practical Teaching System. Some students in information management and information system do not 
have strong practical ability, so that it is difficult to achieve faster and social needs docking. Therefore, it is necessary to strengthen the cultivation of practical ability of the students, especially the practical teaching links [5]. The professional practice under the foundation of the retention of information management social survey, curriculum design, graduation practice, graduation design and other aspects, increase information system project management internship, summer primary, professional comprehensive training and enterprise internship practice teaching links. The excellent talents training practice teaching system of information management is shown in Fig. 3.

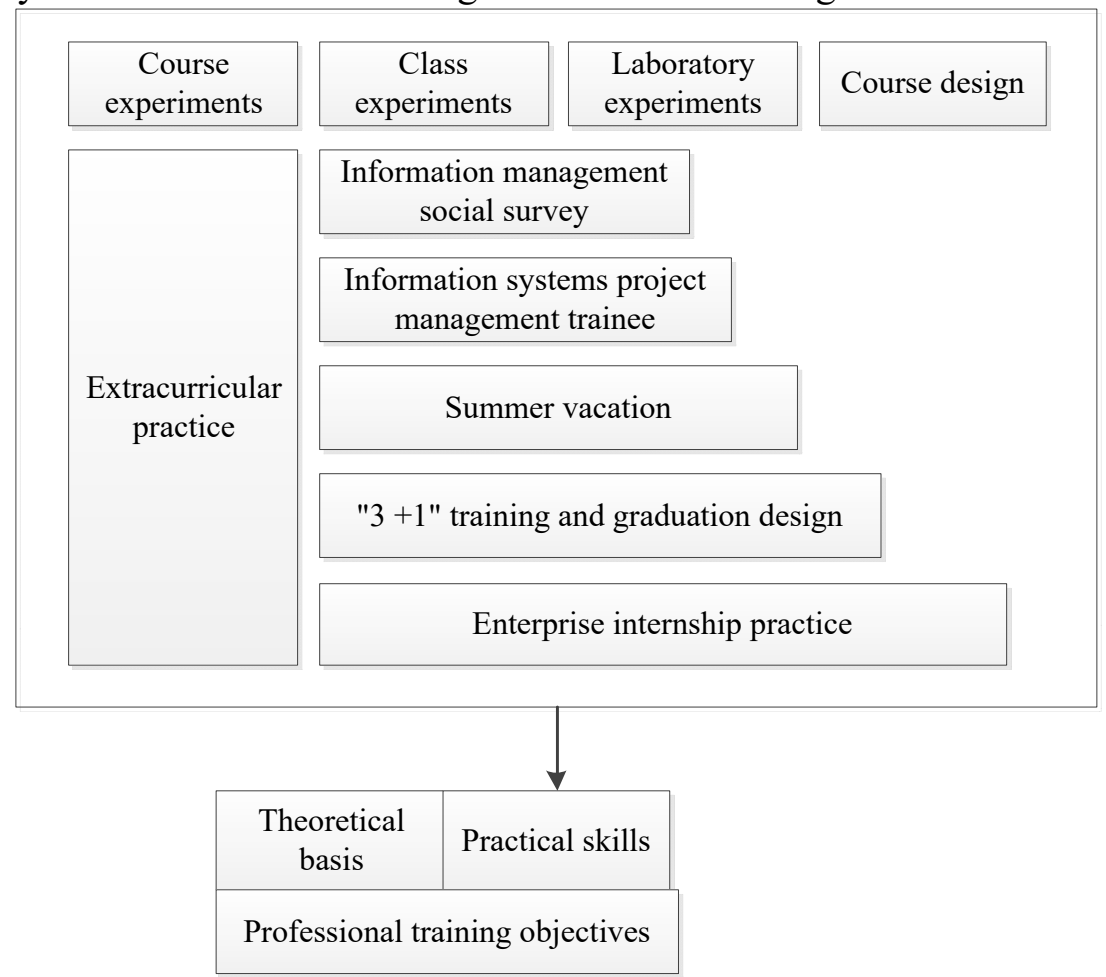

Fig. 3 The excellent talents training practice teaching system of information management

As shown in Fig. 3, the excellent talents training practice teaching system of information management divides the practice teaching contents into two modules: "course experiment" and "after-class practice", which are the key part to train the talents with innovation and practical ability. Through classroom experiments and curriculum design, students can learn and consolidate new knowledge, master the method of scientific experiments. Through the extracurricular practice activities, students can exercise their practical ability to comprehensively improve the overall quality, so that it can achieve a better organic integration between the theory and practice, and promote students practical skills down to earth, and gradually improved.

\section{Conclusions}

Under the Ministry of Education responding to "the construction of local applied undergraduate institutions", learning from the successful experience of domestic and foreign information management talents training, summarizing practical experience, the "Information management and information systems excellent talents training plan" is formed. The new training program better deals with the relationship between course content and social needs. The course setting is reasonable, and the training program optimize the course system and structure, strengthen the basic teaching and practical teaching, focus on students' practical ability. In the development of teaching programs, according to the principles of the school guidance, it is from the reality, accurate positioning, focusing on features, with greater flexibility. Through the implementation of "Information management and information system 
excellent talent training plan," there will be a breakthrough on the training effectiveness of information management major.

\section{Acknowledgements}

This research is supported by the Reform program of Hebei Education Department (2015GJJG300)

\section{References}

[1] Zhang Jie, Li Jie. Characters and optimization of curricular design for information management in universities. Journal of Hebei Normal University, 2009, 11(10): p. 80-83.

[2] Yu Yicheng. Enhancement of practical innovation capability of information management personnel in curriculum collaboration. Research and Exploration in Laboratory, 2013, 32(10): p. 438-442.

[3] Wang Lepeng, Pan Hua. A study on outstanding talent training mode based on 5P method. Technology Square, 2015, 4: p. 126-129.

[4] Zhang Lei, Yang Songtao, Wang Dan. Information management and information system training from the perspective of business need. Computer Knowledge and Technology, 2010, 6(30): p. 8655-8657.

[5] Cui Lin, Lu Hongmei. Research on the excellent talents training plan taking social demands as the guidance of information management and information system. Journal of Anyang Normal college, 2010, 5: p. 122-125. 